\title{
Molecular Control of the Viscosity of Model Dendritically Branched Polystyrene Solutions: From Polymeric to Colloidal Behavior
}

\section{Anthi Asteriadi, ${ }^{\dagger}$ Reinhard Sigel, ${ }^{\ddagger}$ Dimitris Vlassopoulos, ${ }^{*, t, \S}$ Gerd Meier, ${ }^{\perp}$ J ohn R. Dorgan," and Daniel M. Knauss"}

FORTH, Institute of E lectronic Structure and Laser, Heraklion 71110, Crete, Greece, Max-Planck Institut fuer Kolloid und Grenzflaechenforschung, $14476 \mathrm{Golm}$, Germany, Department of Materials Science and Technology, University of Crete, Heraklion 71110, Crete, Greece, Institut fuer

Festkoerperforschung, F orschungszentrum J uelich, J uelich 52425, Germany, Chemical Engineering Department, Colorado School of Mines, Golden, Colorado 80401, and Chemistry Department, Col orado School of Mines, Golden, Colorado 80401

Received October 8, 2003; Revised Manuscript Received November 7, 2003

\begin{abstract}
We explore the concentration dependence of the zero shear viscosity of well-defined dendritically branched polystyrene solutions in relation to their internal structure. Whereas in the past the change of total molecular weight was achieved via change of the number of generations (G) for fixed backbone segment length (average number of units between branches, $P$ ), these unique materials with constant number of generations allow monitoring the molecular weight through variation of $P$. We find that increasing $\mathrm{P}$ yields polymer-like behavior, whereas for lower backbone molecular weights a predominantly colloidal particle-like behavior is observed. Our results further indicate that the static properties (the branching ratio, i.e., the ratio of dendritically branched-to-linear polymer radius of gyration, $\mathrm{g}=\left\langle\mathrm{R}_{\mathrm{g}}{ }^{2}\right\rangle /\left\langle\mathrm{R}_{\mathrm{g}}{ }^{2}\right\rangle_{\text {linear }}$ and scattering intensity) are also sensitive, but to a lesser degree, to the crossover from colloidal to polymeric behavior, especially for the largest molecular weights.
\end{abstract}

\section{Introduction}

Dendrimers have emerged as a relatively new class of highly and regularly branched macromolecules with interesting properties (ranging from processing aids to controlled drug release) and numerous potential applications, depending on their generation, i.e., the number of branching layers. ${ }^{1,2}$ The regularity of their internal structure, very low polydispersity and very low molecular weight between branches (usually just one monomer) make them different from the conventional hyperbranched polymers, ${ }^{3}$ which possess in general a varying degree of branching per layer and a nonnegligible polydispersity, and have been studied extensively as well. A special class of hyperbranched polymers encompassing features from both classes of branched polymers above is that of dendritically branched (or dendritic) polymers, where the molecular weight between branch points can be varied and controlled. Examples of dendritic polymers in this sense, which could also be called Cayley trees, ${ }^{4}$ include arborescent polymers, ${ }^{5}$ dendrigraft polymers, ${ }^{6}$ dendrimer-like star polymers, ${ }^{7}$ and others. ${ }^{8}$

Dendritically branched polymers having a constant but small number of chain segments between branching points (below their entanglement limit) and a low number of generations $(G \leq 5)$ can be compared to starlike branched macromolecules, whereas for larger number of generations ( $>5$ ) they can become more spherelike due to their tightly packed molecular structure. Unique dendritic polystyrenes of generation $\mathrm{G}=$ 5 were recently synthesized using anionic polymeriza-

† FORTH, Institute of Electronic Structure and Laser.

‡ Max-Planck Institut fuer Kolloid und Grenzflaechenforschung.

$\S$ University of Crete.

${ }^{\perp}$ Forschungszentrum J uelich.

" Chemical Engineering Department, Colorado School of Mines.

\# Chemistry Department, Colorado School of Mines. tion techniques; 8 their unique melt rheological properties were investigated and it was found that these macromolecular objects exhibit low zero-shear viscosity and high elasticity. ${ }^{9}$ I deally, such polymers are essentially starburst molecules due to their starlike cascade topology. ${ }^{10}$ However, the procedure employed for the synthesis of the present polymers (convergent living anionic polymerization $)^{8}$ yielded dendritic polymers resembling rooted trees, being far from perfect starburst dendrimers and closer to hyperbranched polymers, yet with low polydispersity and high branching efficiencies.

The unusual solution properties of the polymers with dendritic structures (dendrimers as well as hyperbranched polymers) relate to their architecture and make them attractive candidates for use as rheology modifiers. ${ }^{2-4,9}$ In particular, they possess remarkably low viscosities and high solubilities compared to those of linear polymers with the same total molecular weight. The former is generally attributed to their dense, packed internal structure, $2,8,10-12$ whereas the latter is a consequence of the large number of peripheral terminal groups of the dendritic polymers. $2,8,9$

In recent years, the need to bridge the gap between polymers and colloids has emerged as an important topic in soft matter physics. ${ }^{13,14}$ The reason stems from the desire to explore the behavi or and properties of complex materials exhibiting both polymeric and colloidal features; a typical example is a polymerically stabilized colloidal sphere with varying size of grafted polymeric layer. In this paper, we employ this new series of dendritically branched polystyrenes in order to address some aspects of the problem; in particular, by varying the length of the chain segments between branches we can monitor the "compactness" and thus the softness of the dendritic polymer, and thus we effectively span the polymer-to-coll oid range. We examine the concentration dependence of the zero-shear viscosity of these systems, 
Table 1. Molecular Characteristics of Dendritically Branched Polystyrenes

\begin{tabular}{ccccrr}
\hline $\begin{array}{c}\text { sample } \\
\text { code }\end{array}$ & $\begin{array}{c}\mathrm{M}_{\mathrm{w}} \\
(\mathrm{kg} / \mathrm{mol})^{\mathrm{a}}\end{array}$ & $\begin{array}{c}\mathrm{G} \\
\text { (generation) }^{\mathrm{a}}\end{array}$ & $\begin{array}{c}\text { P (av. no. of } \\
\text { units between } \\
\text { branches) }\end{array}$ & $\begin{array}{c}\mathrm{R}_{\mathrm{g}} \\
(\mathrm{nm})^{\mathrm{b}}\end{array}$ & $\begin{array}{c}\mathrm{R}_{\mathrm{h}} \\
(\mathrm{nm})^{\mathrm{c}}\end{array}$ \\
\hline PS 1:5 & 70 & 4.5 & 3.3 & 5.4 & 5.1 \\
PS 1:10 & 95 & 4.8 & 6.6 & 6.3 & 6.1 \\
PS 1:20 & 213 & 5.6 & 13.2 & 9.4 & 9.1 \\
PS 1:50 & 320 & 5.3 & 33.3 & 11.3 & 11.3 \\
PS 1:100 & 740 & 5.6 & 61.3 & 16.2 & 18.5 \\
PS 1:137 & 863 & 5.2 & 91.3 & 19.6 & 19 \\
PS 1:200 & 1313 & 5.1 & 133.3 & 30.2 & 29.6
\end{tabular}

a From refs 8 and 9. ${ }^{b} R_{g}$ measured in d-toluene at $20^{\circ} \mathrm{C}$. ${ }^{c} R_{h}$ measured in toluene at $20^{\circ} \mathrm{C}$.

and we demonstrate that it is possible to tune at molecular level the properties to meet specific needs. We further show that hard spheres, micelles, stars, dendritic, and linear polymers can fit in a generic master plot of reduced viscosity against volume fraction.

The paper is organized as follows: Section II includes the materials and methods used; the experimental results are presented and discussed in section III and the main conclusions drawn from this work are summarized in section IV.

\section{Experimental Section}

Materials. We used dendritically branched polystyrenes of different molecular weight between branches, all possessing approximately five generations; their main molecular characteristics are listed in Table 1. They were synthesized using a novel method that combines living anionic polymerization with a convergent process in a one-pot reaction, yielding welldefined polymers with polydi spersity $M_{w} / M_{n}<1.5$; details can be found in ref 8 . Numerous samples were prepared in dioctyl phthalate (DOP) at different concentrations ranging from 0.2 to 40 wt \%, spanning the dilute-to-concentrated range. Selected samples were also dissolved in deuterated and protonated toluene for neutron scattering and light scattering measurements, respectively, as discussed below.

Methods. The main experimental tool was shear rheometry (Rheometric Scientific ARES-100FTRN1-HR), for the measurement of the solutions zero-shear viscosities in DOP at 20 or $22{ }^{\circ} \mathrm{C}$ for the mixtures (see below); temperature control of $\pm 0.1^{\circ} \mathrm{C}$ was achieved via a recirculating water-ethylene glycol mixture. Depending on the concentration, Couette (height 13.5 $\mathrm{mm}$, bob diameter $16.5 \mathrm{~mm}$ and cup diameter $17 \mathrm{~mm}$ ) or parallel plate geometries $(25 \mathrm{~mm}$ diameter, $1 \mathrm{~mm}$ sample thickness) were employed. The tests consisted of isothermal dynamic frequency sweeps in the linear viscoelastic regime (which was established with isochronal dynamic strain sweeps) and steady shear rate sweeps. ${ }^{15}$

Some selected small-angle neutron scattering (SANS) measurements were al so carried out with dilute dendritic polymer solutions in deuterated toluene (contained into a $1 \mathrm{~mm}$ thick Hellma quartz cuvettes) at the KWS II, Forschungszentrum J ülich; neutrons were used with a wavelength of $\lambda=6.3 \AA$ and $\Delta \lambda / \lambda \approx 0.18$, at three detector distances $(2,8$, and $20 \mathrm{~m})$ in order to access the wavevector range $0.03<\mathrm{q}\left(\mathrm{nm}^{-1}\right)<1.5$, al lowing one to assess the polymers' form factor and radius of gyration, $\mathrm{R}_{\mathrm{g}}{ }^{16}$ The scattered neutrons were detected with a two-dimensional ${ }^{3} \mathrm{He}$ detector consisting of $64 \times 64$ channels, each of $0.8 \mathrm{~cm}$ width. The count rate was controlled in a way that minimized the dead time effects. The isotropic raw data were radially averaged and corrected for background scattering, and the intensity was converted into absolute units $\left(\mathrm{cm}^{-1}\right)$ by using a polyethylene sample of known incoherent scattering as standard (calibrated against vanadium) and empl oying the J uelich software package DAN. ${ }^{16}$

We also used the dynamic light scattering technique (photon correlation spectroscopy) in order to determine the hydro-

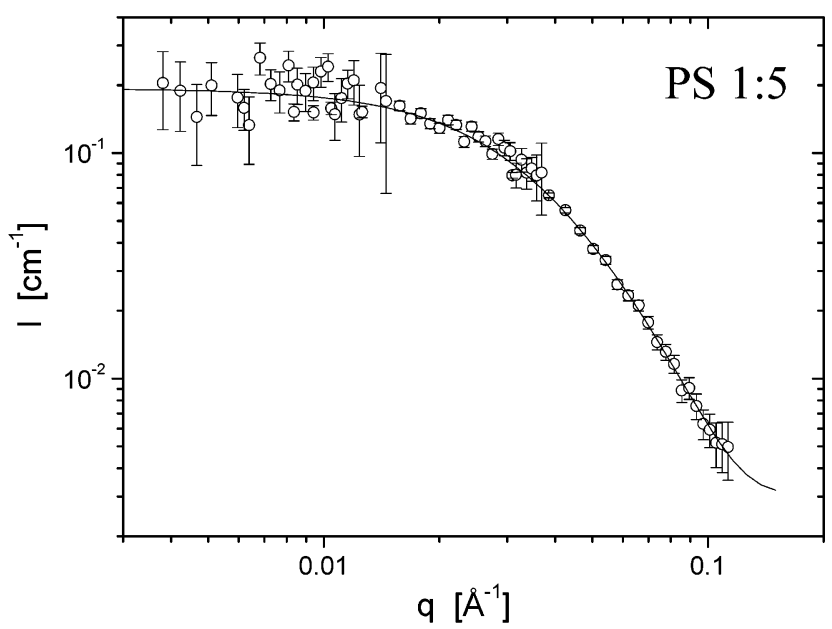

Figure 1. SANS intensity as a function of scattering wavevector $q$, for a dilute solution (1 wt \%) of PS 1:5 in d-toluene. The line is the fit of eq 1 to the data.

dynamic radii of these systems (single dendritic polymers in very dilute solution, in the concentration range $0.08-0.1 \mathrm{wt}$ $\%), R_{h}$. An ALV goniometer setup and an ADLAS Nd:YAG laser operating at $\lambda=532 \mathrm{~nm}$ were utilized. The Brownian motion of a dendritic polymer was detected through the concentration fluctuations of the system at different scattering wavevectors $q=(4 \pi n / \lambda) \sin (\theta / 2)$, $n$ being the refractive index of the solvent and $\theta$ the scattering angle. The measurement consisted of obtaining the intermediate scattering (field) function $\mathrm{C}(\mathrm{q}, \mathrm{t})=\left[(\mathrm{G}(\mathrm{q}, \mathrm{t})-1) / \mathrm{f}^{*}\right]^{1 / 2}$ in the polarized $(\mathrm{VV})$ geometry, where $f *$ is an instrumental factor relating to the coherence area (for details, see ref 17) and the time autocorrelation function of the scattered intensity $G(q, t)$ was determined with an ALV-5000/E fast multi- $\tau$ correlator in the time range $10^{-7}-10^{3} \mathrm{~s}$. The inverse $L$ aplace transformation of the $\mathrm{C}(\mathrm{q}, \mathrm{t})$ (obtained using the CONTIN software), $\mathrm{C}(\mathrm{q}, \mathrm{t})=\int \mathrm{L}(\mathrm{In}$ $\tau) \exp (-t / \tau) d(\ln \tau)$ was used to determine the continuous spectrum of relaxation times $L(\ln \tau)$, which was subsequently fitted with a Gaussian function in order to obtain the characteristic relaxation time $\tau$; from the latter, the diffusion coefficient was extracted $D=1 /\left(\tau q^{2}\right)$. The equivalent hydrodynamic radius was obtained from $\mathrm{R}_{\mathrm{h}}=\mathrm{kT} / 6 \pi \eta_{\mathrm{s}} \mathrm{D}$ ( $\mathrm{k}$ being the Boltzmann constant and $\eta_{\mathrm{s}}$ the solvent viscosity), assuming validity of the Stokes-Einstein relation for spherical objects.

\section{Results and Discussion}

III.1. Conformational Features. Figure 1 depicts a typical result of the wavevector dependence of the SANS intensity for the dilute (1wt \%) sample PS 1:5 in d-toluene. Since in the di lute region the structure factor is $S(q) \approx 1$, the scattering intensity is essentially the form factor, $I(q) \approx P(q)$. From the fitting of the data to the Guinier expression (for a q range around $\mathrm{R}_{\mathrm{g}}{ }^{-1}$ ), ${ }^{18}$

$$
I(q)=I_{0} e^{-q^{2} R_{g}^{2} / 3}
$$

we can extract the plateau value of the intensity (thermodynamic limit), $I_{0}=I(q \rightarrow 0)$, and the value of $\mathrm{R}_{\mathrm{g}}$. Alternatively, the $\mathrm{R}_{\mathrm{g}}$ values were obtained from the so-called Berry plots. ${ }^{19} \mathrm{~A}$ typical example is depicted in Figure 2 which plots the intensity (form factor) against $\mathrm{q}^{2}$; the linear fit to the low-q data yields the radius of gyration. The obtained values of $R_{g}$ and $R_{h}$ (from dynamic light scattering) in toluene are depicted in Table 1.20

The dependence of $R_{g}$ on molecular weight for such dendritic structures merits special attention. For good solvent conditions (with excluded volume interactions) 


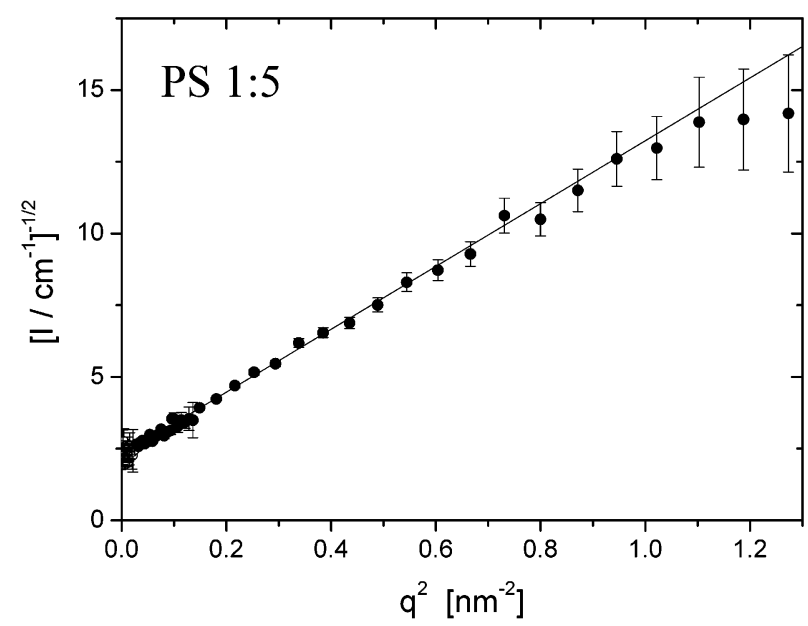

Figure 2. Inverse square route of SANS intensity $(1 / \sqrt{I})$ against $\mathrm{q}^{2}$ for the PS1:5 data of Figure 2 (Berry plot).

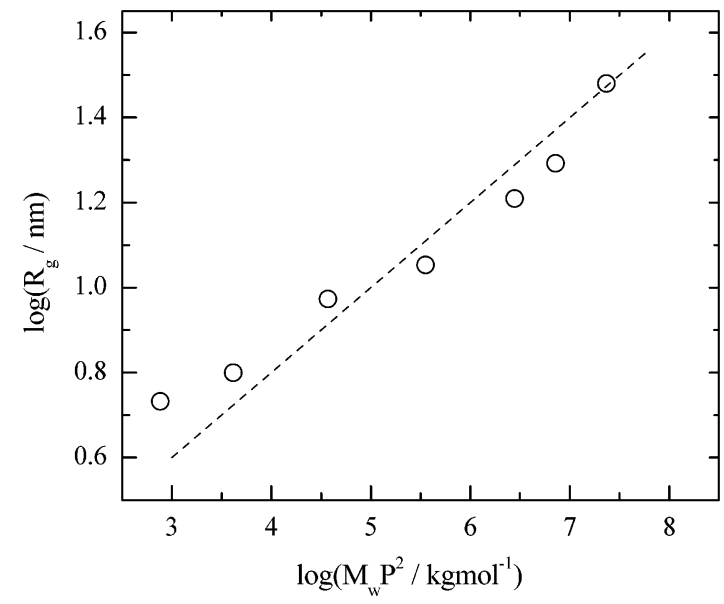

Figure 3. Dependence of the radius of gyration of the dendritic polystyrenes in toluene at $20{ }^{\circ} \mathrm{C}(\mathrm{O})$ on the product $\mathrm{M}_{\mathrm{w}} \mathrm{P}^{2}$ (see eq 2 in text). The dashed line represents the theoretical slope of 0.2 .

the following dependence was derived from scaling arguments: ${ }^{21}$

$$
R_{g} \propto N^{1 / 5}(G+1)^{2 / 5} P^{2 / 5}
$$

It was shown that this holds for the simulated dendrimers in the range $P=1$ to 50 ( $P$ being the number of units between branch points) and number of generations $\mathrm{G}=1$ to 7 . The total number of monomer units was $\mathrm{N}$ $=f P\left[(f-1)^{G+1}-1\right] /(f-2)+1$ where $f$ is the functionality of the branch point ( $f=3$ here). Similar results with identical or slightly different exponents were reported in earlier mean-field theoretical model $s^{22,23}$ and simulation studies, irrespective of solvent quality. $10,24,25$

In all experimental and simulation work on dendrimer systems to date, $\mathrm{P}$ was kept constant and $\mathrm{G}$ was varied; ${ }^{10,21,24-26}$ it was observed that $R_{g}$ exhibited an overall $\mathrm{N}^{0.3}$ dependence (accounting for the fact that $\mathrm{N}$ can vary with $P$ and/or $G$ ). ${ }^{21}$ The dependence of $R_{g}$ of dendrimers on $\mathrm{P}$ has never been explored experimentally, because of the synthetic difficulties. The unique samples at hand with their nearly constant generation number ${ }^{8}$ allow this for the first time. Indeed, this is demonstrated in Figure 3, which represents the application of eq 2. Given the small uncertainty in the data
Table 2. Comparison of the Size Ratios of Different Branched Polymers with nearly the Same Number of Branches

\begin{tabular}{ccc}
\hline sample code & $\mathrm{R}_{\mathrm{g}} / \mathrm{R}_{\mathrm{h}^{\mathrm{a}}}$ & $\mathrm{g}^{\mathrm{b}}$ \\
\hline PS $1: 5$ & 1.059 & 0.377 \\
PS 1:10 & 1.033 & 0.359 \\
PS 1:20 & 1.033 & 0.310 \\
PS 1:50 & 1 & 0.279 \\
PS 1:100 & 0.876 & 0.215 \\
PS 1:137 & 1.032 & 0.263 \\
PS 1:200 & 1.02 & 0.382 \\
C622 & 1.139 & 0.563 \\
C732 $^{\mathrm{d}}$ & 1.225 & 0.696 \\
S64 $^{\mathrm{e}}$ & 0.781 & 0.07
\end{tabular}

${ }^{1}$ In toluene. ${ }^{2}$ Static property (branching ratio):27,31,32 $\mathrm{g}=\left\langle\mathrm{R}_{\mathrm{g}}{ }^{2}\right\rangle /$ $\left\langle\mathrm{R}_{\mathrm{g}}{ }^{2}\right\rangle_{\text {linear, }}$ in toluene. The linear polymer has the same (total) molecular weight as the dendritic one. Its $R_{\mathrm{g}}$ was obtained from ref $32 .{ }^{3}$ Comb polystyrene from ref 30 . Number of branches $p=$ 30; backbone segment molecular weight $M=9166$; branch molecular weight $\mathrm{M}_{\mathrm{br}}=11700 .{ }^{4}$ Comb polystyrene from ref 30 . Number of branches $\mathrm{p}=30$; backbone segment molecular weight $M=28670$; branch molecular weight $M_{b r}=25700 .{ }^{5}$ Multiarm star 1,4-polybutadiene from ref 31 . The number of arms ranges from 56 to 62 , and the arm molecular weight ranges from 6330 to 71000 .

$\left(R_{\mathrm{g}}\right.$ determination as discussed above, small polydispersity and the small variation of $\mathrm{G}$ ), their agreement with the dendrimer model is reasonably good to justify the claim that the data conform to this model. Note that eq 2 can also be applied to the $R_{h}$ data with the same results as in Figure 3 (not shown here). Therefore, to a first approximation, the dimensions of the present dendritical ly branched polystyrenes scale like starburst dendrimers.

Theratio $R_{g} / R_{h}$ for the different dendritic polystyrenes is listed in Table 2 and found to be nearly 1 (actually, it varies from 0.88 to 1.06$),{ }^{20}$ indicating that these systems exhibit a behavior between hard spheres $\left(R_{0}\right)$ $\left.R_{h}=0.77\right)$ and flexible polymers $\left(R_{g} / R_{h}=1.47-\right.$ 1.50). 27,28 Note that for particles with spherical symmetry this ratio assumes its maximum value of 1 in the case of hollow spheres (e.g., vesicles); ${ }^{28}$ the present dendritic polymers, as well as the polymer coils, are not truly spherically symmetric, and thus a logical analogy to hollow spheres is not fully justifiable in this respect. On the other hand, it is possible that the dendritic polymers might have a wedgel ike shape. Furthermore, the fact that $R_{o} / R_{h}$ is virtual ly independent of molecular weight suggests that these dendritic structures (with nearly constant $\mathrm{G}$ ) are self-similar.9,29 Furthermore, to assess the properties of the present dendritic polymers, it is useful to compare them with other well-defined branched polymers. In this respect, we consider model star and comb polymers based on the number of branching units as follows: The present dendritic polystyrenes have an average of 60 segments. Table 2 lists the static and hydrodynamic properties of two comb polystyrenes having on average 30 side-branches and a branch length virtually of the same size as the backbone segment between two branching points (C622 and C732), ${ }^{30}$ thus effectively representing branched systems with a total of 60 branches on average. This table also includes regular nominally 64-arm 1,4-polybutadiene stars (coded as S64) ${ }^{31}$ which can be thought of as a regularly branched polymer of nearly spherical conformation, with about 60 branches. It can be also seen from this Table that the static property ${ }^{27,31,32} \mathrm{~g}=\left\langle\mathrm{R}_{\mathrm{g}}{ }^{2}\right\rangle /$ $\left\langle\mathrm{R}_{\mathrm{g}}{ }^{2}\right\rangle_{\text {linear }}$ (branching ratio) is weakly sensitive to the differences in branch molecular weight, and thus compactness, of the dendritic polystyrenes (small difference 


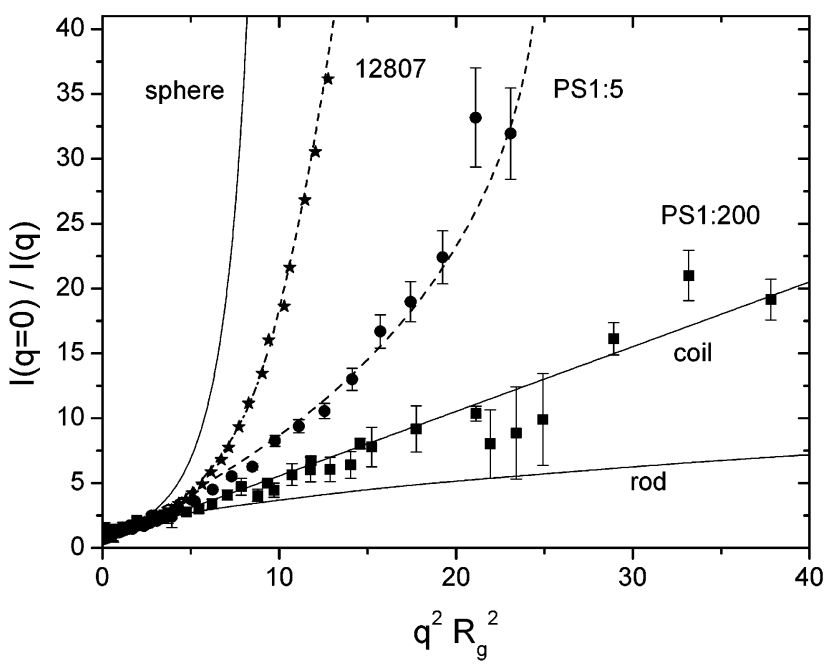

Figure 4. I nverse normalized SANS intensity I $(q=0) / I(q)$ against $q^{2} R_{g}{ }^{2}$. Dashed lines through the data are drawn to guide the eye. The solid lines represent theoretical predictions for sphere, coil and rod.

of g values among samples), with increasing sensitivity for the largest molecular weights examined; this could suggest possible means of distinguishing the different dendritic polymers. One may also conclude from Table 2 that the dendritic polymers at hand are clearly different from the multiarm star polymers, and reasonably close to the comb polymers. In fact, their g values are in the range of typical values exhibited by conventional hyperbranched polymers (between 0.22 and 0.44 for a number of branches in the range 10-400) ${ }^{3}$.

Figure 4 plots the ratio $\mathrm{I}_{0} / \mathrm{l}(\mathrm{q})$ against the square of the dimensionless size, $q^{2} R_{g}^{2}$ for the two limiting samples PS 1:5 and PS 1:200, al ong with the theoretical curves for a (hard) sphere, and the two polymeric counterparts, a flexible coil and a rigid rod. ${ }^{16,28} \mathrm{~A}$ difference between the two samples is evident, although not dramatic: PS 1:5 with smaller molecular weight between branches (and thus total molecular weight) is more compact and appears to be closer to a sphere, whereas sample PS 1:200 has a more extended, loose structure resembling that of a polymeric coil. For comparison, we have included in this plot data from a well-studied model multiarm star polymer, PBd12807, i.e., a 1,4-polybutadiene regular star possessing nominally 128 arms and arm molecular weight 7000.31 The SANS data were obtained from measurements in $\mathrm{d}$ methylcyclohexane (12807). ${ }^{33}$ It can be seen that the star exhibits more regular spherical shape than the dendritic polymers, as judged from its closer proximity to the sphere limit. Therefore, this type of representation could possibly offer (along with the dynamic data discussed bel ow) a means of classification of the different branching architectures with respect to their conformation. Note that the intermediate dendritic polystyrene molecular weights are situated between the two limiting cases of Figure 4, suggesting that tuning the layer molecular weight offers a means to control the dendritically branched polymer conformation. Alternatively, a Kratky plot of I $\mathrm{q}^{2}$ against q (not shown here) shows the difference between PS 1:5 and PS 1:200, as the more particle-like former dendritic polymer exhibits a clear peak, whereas the latter does not.

III.2. Rheological Features. Figure 5 depicts the relative viscosity $\left(\eta_{0} / \eta_{\mathrm{s}}\right.$, with $\eta_{0}$ the zero shear viscosity and $\eta_{\mathrm{s}}$ the solvent viscosity) as a function of effective

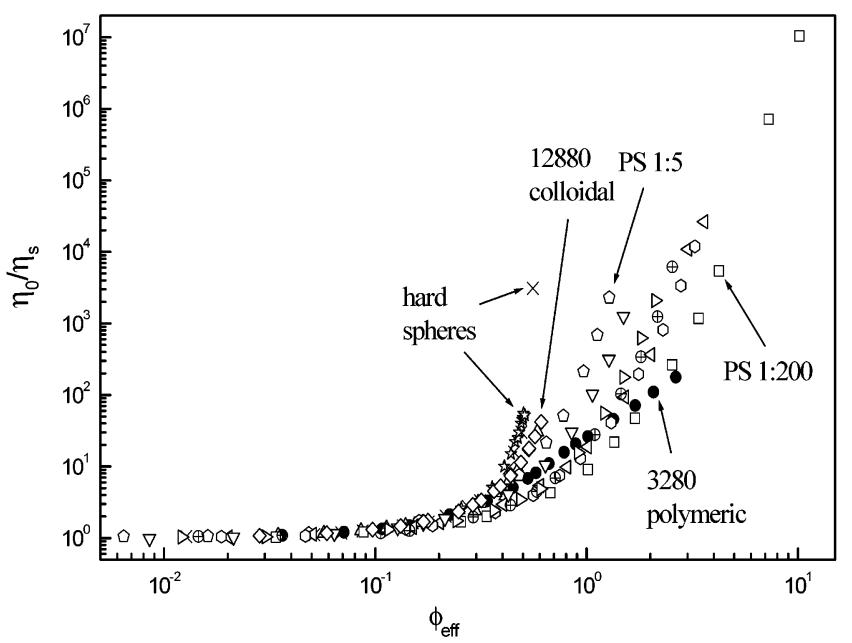

Figure 5. Relative zero-shear viscosity, $\eta_{0} / \eta_{\mathrm{s}}$, against effective volume fraction, $\phi_{\text {eff }}$ (based on the hydrodynamic radius at 20 ${ }^{\circ} \mathrm{C}$ ) for the dendritically branched systems (PS1:5, pentagon; $\mathrm{PS} 1: 10, \nabla ; \mathrm{PS} 1: 20$, triangle pointing right; PS1:50, $\oplus$; PS1:100, hexagon; PS1:137, triangle pointing left; PS1:200, $\square$ ). In this plot some typical data from multiarm star polymers (128 arms, arm molecular weight $\mathrm{M}_{\mathrm{a}}=80 \mathrm{~K}, 12880, \diamond ; 128$ arms, $M_{a}=7 \mathrm{~K}, 12807, \triangle ; 32$ arms, $\left.M_{a}=80 \mathrm{~K}, 3280,0\right)$ and hard sphere colloids (PMMA in Decal in $640 \mathrm{~nm}$ radius, 2 ; 602 $\mathrm{nm}$ radius, $\times$ ) are also included for comparison (see also refs 34-37).

volume fraction ( $\varphi_{\text {eff }}$ ) for the seven different dendritic polystyrenes of Table 1 in DOP at $20{ }^{\circ} \mathrm{C}$. The latter quantity represents the volume fraction of an effective sphere with dimension the overall hydrodynamic radius of the soft particle $\left(R_{h}\right),{ }^{34}$ and is equivalent to the normalized concentration, $c c^{*}$, where $c^{*}$ is the overlapping concentration. DOP is a $\Theta$ solvent for linear polystyrene at $21^{\circ} \mathrm{C},{ }^{32}$ but on the other hand branching (similar to that in the present systems, where there are in the macromolecule chain segments between branches) is known to result in a reduction of the theta temperature. ${ }^{11}$ On the basis of this, as well as on basis of the fact that the measured $R_{h}$ values in toluene (good solvent) and DOP (used for the determination of $\varphi_{\text {eff, }}$ and not shown here) at $20{ }^{\circ} \mathrm{C}$ exhibit the same dependence on the total molecular weight (eq 2), we claim that at this temperature DOP is a good solvent for the dendritically branched polystyrenes at hand. In Figure 5 , some representative data from multiarm star polymers ${ }^{35}$ (with 128 and 32 arms, resembling hard colloids and polymer coils, respectively) and hard sphere colIoidal dispersi ons ${ }^{36,37}$ used in a previous work ${ }^{34}$ are also included. It is remarkable that data from all these different systems can be put together in a generic plot when their hydrodynamic radius is considered for the estimation of the $c^{*}$ and thus the effective volume fraction. ${ }^{34,38}$ F urthermore, an important finding is the fact that the dendritic samples with the same generation $\mathrm{G}$ (Table 1 ) and similar values of the ratio $\mathrm{g}$ (Table 2 ) exhibit different viscosity-volume fraction behavior (different curves). In particular, it can be observed that at high volume fractions the dendritic polymer with the smallest total molecular weight (PS1:5) exhibits a steeper volume fraction dependence compared to its counterparts, approaching the behavior of multiarm stars and hard spheres. On the other hand, the system with the largest total molecular weight (PS1:200) appears to behave more like a flexible polymer solution. This difference in behavior of dendritic polystyrenes with the same number of generations reflects the 
Table 3. Overlapping Concentration ( $\left.c^{*}\right)$ and Best Fit Parameters of Dendritic Polystyrene Data to the Krieger-Dougherty and Martin Equations

\begin{tabular}{cccc}
\hline sample code & $\mathrm{c}^{*}(\mathrm{~g} / \mathrm{mL})^{\mathrm{a}}$ & $\phi_{\mathrm{m}}{ }^{\mathrm{b}}$ & $\mathrm{K}^{\mathrm{c}}$ \\
\hline PS $1: 5$ & 0.30 & 1.28 & \\
PS $1: 10$ & 0.23 & 2.76 & \\
PS $1: 20$ & 0.16 & 3.87 & \\
PS $1: 50$ & 0.13 & & 0.89 \\
PS $1: 100$ & 0.10 & & 0.68 \\
PS $1: 137$ & 0.09 & & 0.73 \\
PS $1: 200$ & 0.06 & & 0.62
\end{tabular}

a Estimated in DOP at $20{ }^{\circ} \mathrm{C}$. b From Krieger-Dougherty, eq 3. ' From Martin, eq 4.

difference in molecular weights between branches, as already discussed. PS 1:5 is more compact and reminiscent of colloidal spheres (with soft interactions), whereas PS1:200 has a much looser structure and exhibits a nearly polymeric behavior. An intermediate behavior is observed for the intermediate molecular weights samples (PS1:10 to PS1:137) reflecting a increasingly softer interaction as the molecular weight between branches increases; the turning point from predominantly colloidal to predominantly polymeric behavior is apparently set at the PS1:50 sample and relates to the phenomenological fitting of the data, as discussed below. Note that all the data of Figure 5 collapse into a master curve for low-volume fractions $\varphi_{\text {eff }}<0.08$ (the Einstein limit, $\eta_{0} / \eta_{\mathrm{s}}=1+2.5 \phi_{\text {eff }}$ ); this suggests that the effective volume fraction is an appropriate composition variable for these systems.

To obtain a quantitative description of the concentration dependence of the zero-shear viscosity several expressions have been proposed in the literature. ${ }^{39-41}$ For the present set of data, we attempted fitting with established semiempirical relations for two limiting cases, colloids and polymers, as follows. The KriegerDougherty empirical relation, $37,41,42$

$$
\frac{\eta_{0}}{\eta_{\mathrm{s}}}=\left(1-\frac{\phi_{\text {eff }}}{\phi_{\mathrm{m}}}\right)^{-2.5 \phi_{\mathrm{m}}}
$$

proposed to describe the viscosity-concentration curves of colloidal spheres close to the hard sphere limit (here 2.5 is the Einstein value for hard spheres) did not give very satisfying results, even for the dendritic polymers with the two lowest molecular weights (most compact, i.e., closer to the hard sphere behavior). This equation can be used in principle to determine the "effective cl ose packing" volume fraction at which the viscosity diverges, $\phi_{m}$, by considering the dendritic polystyrenes as effective hard spheres. ${ }^{38}$ In such a case all softer than hard sphere particles would exhibit $\phi_{m}>0.67$, as observed even by eye in Figure 5 . In the present case the values of $\phi_{\mathrm{m}}$ cover the range $1.28<\phi_{\mathrm{m}}<3.87$ (see Table 3 and Figure 6 below); similar values of $\phi_{\mathrm{m}}$ have been reported for other dendritic polymers recently. ${ }^{38}$ Still, the fit of eq 3 to the data is far from perfect; one possible origin for the deviations could bethe not truly spherical (rather wedgelike) shape of the dendritic polymers, which could also lead to a distinct geometrical packing compared to purely spherical objects. ${ }^{40}$ Obviously, this equation cannot describe polymeric behavior. Similar conclusions with respect to the classification of the dendritic polystyrenes are drawn from the use of the Quemada form of the Krieger-Dougherty equation (which is similar to eq 3 but has an exponent of -2 ). ${ }^{37,43}$ Note that, in a recent study of the volume fraction dependent zero-

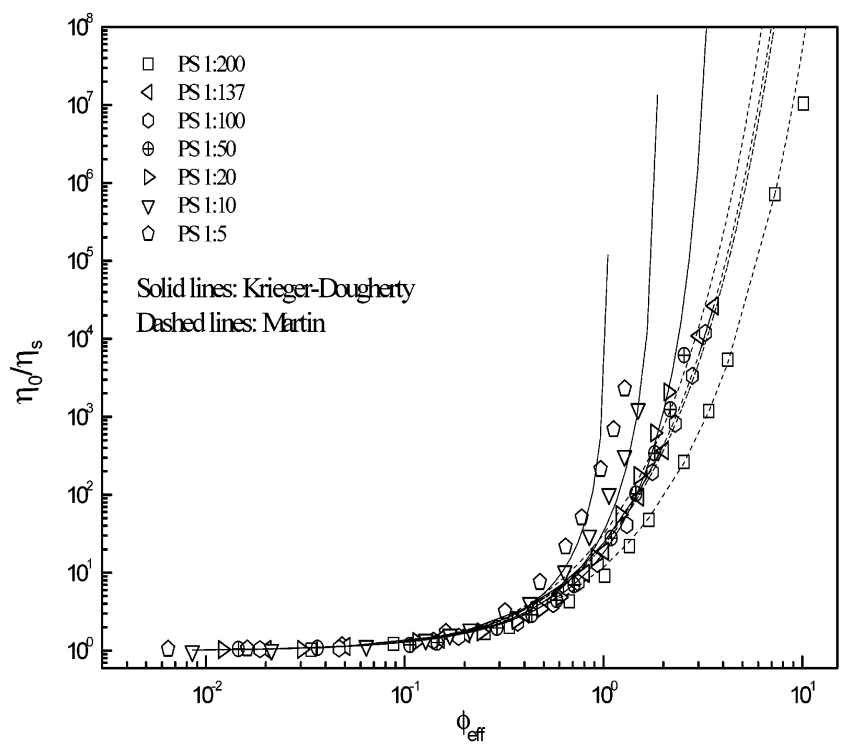

Figure 6. Relative zero-shear viscosity $\eta_{0} / \eta_{\mathrm{s}}$ against effective volume fraction, $\phi_{\text {eff, }}$ based on the hydrodynamic radius, for the dendritically branched systems at $20^{\circ} \mathrm{C}$. Solid lines are fits to the Krieger-Dougherty (eq 3 ) and dashed lines to Martin (eq 4) equations.

shear viscosity of dendrimers, ${ }^{44}$ the viscosity increase at high volume fractions (which remained 2 orders of magnitude lower than those of the present work) for the higher generation dendrimers was found to be much smaller than the Krieger-Dougherty expectation; this was attributed to the breakdown of the solvation layer.

For the samples beyond PS1:50 (which are closer to polymeric chains) we used the Martin equation to describe the viscosity-concentration curves, 45 as the Krieger-Dougherty equation did not produce reasonable fits:

$$
\frac{\eta_{0}}{\eta_{\mathrm{s}}}=1+2.5 \phi_{\mathrm{eff}} \mathrm{e}^{2.5 \mathrm{~K} \phi_{\mathrm{eff}}}
$$

This equation best describes the viscosity-concentration relationship in polymer solutions, and fails for systems exhibiting strong concentration dependence such as soft spheres. The constant $\mathrm{K}$ (listed in Table 3 for different dendritic samples) provides a measure of polymerpolymer interactions in a given solvent and its decrease denotes an enhanced quality of the solvent.

The fits of the predictions to the dendritic polystyrene data are presented in Figure 6, where PS1:5-PS1:20 were fitted with the Krieger-Dougherty equation and PS1:50-PS1:200 with the Martin equation. The message that emerges from the present data and analysis is that these unique dendritic polymers with constant number of generations $G$ can behave either as linear flexible polymers or as soft colloids and their rheological behavior can be molecularly tuned (through the number and size of branches) at wish; in this respect, although distinct species in terms of internal structure, they do exhibit similarities and complementarities with spherical particles having chemically grafted linear chains, micelles, microgels, sterically stabilized colloids, deformable colloidal particles, and colloidal stars. ${ }^{32,46-50}$

\section{Concluding Remarks}

The present study focused on the concentration dependence of the zero shear viscosity of a unique series 
of well-characterized dendritic polystyrenes, with virtually the same number of generations, G, and varying (the average) branch segment length, in relation to their internal structure. Our results indicate that these dendritic polymers with similar values of the ratio $\mathrm{g}=$ $\left\langle\mathrm{R}_{\mathrm{g}}{ }^{2}\right\rangle /\left\langle\mathrm{R}_{\mathrm{g}}{ }^{2}\right\rangle_{\text {linear }}$ exhibit different viscosity-volume fraction behavior. In particular, for higher backbone segment length (and thus total molecular weight) the dendritic system behaves as a flexible polymer, whereas on the other hand for lower molecular weights the system exhibits a predominantly colloidal particle-like behavior. We also find that static properties ( $\mathrm{g}$ and scattering intensity) are weakly sensitive to the internal structure of the polymers (and thus the crossover between colloidal and polymeric behavior); however, they seem to become increasingly more sensitive for the largest molecular weights. These results could potentially offer a means for classifying dendritic polymers with respect to their properties and further tuning their rheology at the molecular level.

Acknowledgment. J .R.D. thanks FORTH for partial support during his sabbatical leave (2001). D.M.K. acknowledges the support of NSF through a CAREER Award (DMR9985221). Tianzi Huang and Hasan Al-Muallem are thanked for the synthesis of the dendritic polystyrenes. D.V. would like to acknowledge many enlightening discussions with and constructive comments by J acques Roovers. Partial support from the EU (Grant HPRN-CT-2000-00017) is gratefully acknowledged.

\section{References and Notes}

(1) Frechet, J . M. J . Science 1994, 263, 1710. Matthews, O. A.; Shipway, A. N.; Stoddart, J. F. Prog. Polym. Sci. 1998, 23, 1. Hawker, C. J . Curr. Opin. Colloid InterfaceSci. 1999, 4, 117 Tomalia, D. A.; Naylor, A. M.; Goddard, W. A., III. Angew. Chem., Int. Ed. Engl. 1990, 29, 138. Grayson, S. M.; Frechet, J. M. J. Chem. Rev. 2001, 101, 3819.

(2) Wooley, K. L.; Frechet, J . M.; Hawker, C. J . Polymer 1994, 35, 4489. Tande, B. M.; Wagner, N. J .; Mackay, M. E.; Hawker, C. J .; J eong, M. Macromolecules 2001, 34, 8580. Uppurli, S.; Keinath, S. E.; Tomalia, D. A.; Dvornic, P. R. Macromol ecules 1998, 31, 4498. Uppurli, S.; Morrison, F. A.; Dvornic, P. R. Macromolecules 2000, 33, 2551. Sagidullin, A. I.; Muzafarov, A. M.; Krykin, M. A.; Ozerin, A. N.; Skirda, V. D.; I gnat'eva, G. M. Macromol ecules 2002, 35, 9472. Hawker, C. J .; Farrignton, P. J .; Mackay, M. E.; Wooley, K. L.; Frechet, J. M. J . J . Am. Chem. Soc. 1995, 117, 4409. Farrington, P. J .; Hawker, C. J .; Frechet, J. M. J .; Mackay, M. E. Macromolecules 1998, 31, 5043. Likos, C. N.: Schmidt, M.: Loewen, H.; Balauff, M.; Poetschke, D.; Lindner, P. Macromolecules 2001, 34, 2914.

(3) Simon, P. F. W.; Mueller, A. H. E.; Pakula, T. Macromolecules 2001, 34, 1677. Sendijarevic, I.; McHugh, A. J. Macromolecules 2000, 33, 590. Robertson, C. G.; Roland, C. M.; Paulo, C.; Puskas, J . E. J . Rheol. 2001, 45, 759. Robertson, C. G.; Roland, C. M.; Puskas, J. E. J. Rheol. 2002, 46, 307. Numez, C. M.; Chiou, B.-S.; Andrady, A. L.; Khan, S. A. Macromolecules 2000, 33, 1720. Gelade, E. T. F.; Goderis, B.; de Koster, C. G.; Meijerink, N.; van Benthem, R. A. T. M.; Fokkens, R.; Nibbering, N. M. M.; Mortensen, K. Macromolecules 2001, 34, 3552. Kharchenko, S. B.; Kannan, R. M. Macromol ecules 2003, 36, 407. Suneel; Buzza, D. M. A.; Groves, D. J McLeish, T. C. B.; Parker, D.; Keeney, A. J .; Feast, W. J . Macromol ecules 2002, 35, 9605.

(4) Blackwell, R. J .; Harlen, O. G.; McLeish, T. C. B. Macromolecules 2001, 34, 2579. Chalari, I.; Hadjichristidis, N.J . Polym. Sci., A: Polym. Chem. 2002, 40, 1519. Zimm, B. H.; Stockmayer, W. H. J . Chem. Phys. 1949, 17, 1301.

(5) Gauthier, M.; Moeller, M. Macromolecules 1991, 24, 4548. Sheiko, S. S.; Gauthier, M.; Moeller, M. Macromol ecules 1997, 30, 2343. Hempenius, M. A.; Zoetelief, W. F.; Gauthier, M.; Moeller, M. Macromolecules 1998, 31, 2299.
(6) Tomalia, D. A.; Dvornic, P. R.; U ppuluri, S.; Swanson, D. R.; Balogh, L. Polym. Mater. Sci. Eng. 1997, 77, 95. Tomalia, D. A.; Hedstrand, D. M.; Ferritto, M. S. Macromolecules 1991, 24, 1435.

(7) Trollsas, M.; Hedrick, J . L. J . Am. Chem. Soc. 1998, 120, 4644. Trollsas, M.; Atthof, B.; Wuersch, A.; Hedrick, J . L.; Pople, J. A.; Gast, A. P. Macromol ecules 2000, 33, 6423

(8) Knauss, D. M.; Al-Muallem, H. A.; Huang, T.; Wu, D. T. Macromolecules 2000, 33, 3557.

(9) Dorgan, J . R.; Knauss, D. M.; Al-Muallem, H. A.; Huang, T.; Vlassopoulos, D. Macromol ecules 2003, 36, 380.

(10) Lescanec, R. L.; Muthukumar, M. Macromol ecules 1990, 23, 2280.

(11) Striolo, A.; Prausnitz, J. M.; Bertucco, A.; Kee, R. A.; Gauthier, M. Polymer 2001, 42, 2579.

(12) Scherrenberg, S.; Coussens, B.; van Vliet, P.; Edouard, G.; Brackman, J .; de Brabander, E.; Mortensen, K. Macromolecules 1998, 31, 456

(13) Vlassopoulos, D.; Fytas, G.; Pakula, T.; Roovers, J . J . Phys. C: Condens. Matter 2001, 13, R855. Seghrouchni, R.; Seghrouchni, R.; Petekidis, G.; Vlassopoulos, D.; Fytas, G.; Semenov, A. N.; Roovers, J .; Fleischer, G. Europhys. Lett. 1998, 42, 271.

(14) Likos, C. N. Phys. Rep. 2001, 348, 267.

(15) Macosko, C. W. Rheology: Principles, measurements and applications; VCH: New York, 1994.

(16) Higgins, J . S.; Benoit, H. Polymers and neutron scattering; Oxford: New York, 1994. Brueckel, T.; Heger, G.; Richter, D., Eds. Neutron scattering, Lectures of the 5th Laboratory course Schriften des Forschungszentrum J uelich (Matter and Materials 9), Forschungszentrum J uelich, J uelich, Germany, 2001.

(17) Berne, B.; Pecora, R. Dynamic Light Scattering; Wiley: New York, 1976.

(18) Stiakakis, E.; Vlassopoulos, D.; Loppinet, B.; Roovers, J .; Meier, G. Phys. Rev. E 2002, 66, 051804. Dozier, W. D.; Huang, J. S.; Fetters, L. J . Macromol ecules 1991, 24, 2810.

(19) Berry, G. C. J . Chem. Phys. 1966, 44, 4550.

(20) Note that there is a slight difference between the $R_{g}$ data of Table 1 and those reported in ref 9, which does not affect any of the conclusions and is due to the less-accurate preliminary analysis of the SANS data in the latter case.

(21) Sheng, Y.-J .; J iang, S.; Tsao, H.-K. Macromolecules 2002, 35 7865.

(22) DeGennes, P. G.; Hervet, H. J . Phys., Lett. 1983, 44, L351.

(23) Boris, D.; Rubinstein, M. Macromolecules 1996, 29, 7251.

(24) Murat, M.; Grest, G. S. Macromolecules 1996, 29, 1278.

(25) Karatasos, K.; Adolf, D. B.; Davies, G. R. J . Chem. Phys. 2001, $115,5310$.

(26) Choi, S.; Briber, R. M.; Bauer, B. T.; Topp, A.; Gauthier, M.; Tichagwa, L. Macromol ecules 1999, 32, 7879. Stechemesser, S.; Eimer, W. Macromolecules 1997, 30, 2204.

(27) Grest, G. S.; Fetters, L. J .; Huang, J . S.; Richter, D. Adv. Chem. Phys. 1996, XCIV, 67. Fetters, L.J .; Hadjichristidis, N.; Lindner, J. S.; Mays, J. W. J . Phys. Chem. Ref. Data 1994, 23, 619.

(28) Burchard, W. Adv. Polym. Sci. 1983, 48, 1.

(29) Trappe, V.; Burchard, W. In Light scattering and photon correlation spectroscopy; Pike, E. R., Abbiss, J. B., Eds.; Kluwer: Dordrecht, 1997.

(30) Roovers, J . Polymer 1979, 20, 843. Roovers, J .; Graessley, W. W. Macromol ecules 1981, 14, 766.

(31) Roovers, J .; Zhou, L. L.; Toporowski, P. M.; van der Zwan, M.; I atrou, H.; Hadjichristidis, N. Macromolecules 1993, 26, 4324.

(32) Brandrup, J ., I mmergut, E. H., Eds. Polymer Handbook, 3rd ed.; Wiley: New York, 1989.

(33) Wilner, L.; J ucknischke, O.; Richter, D.; Roovers, J .; Zhou, L. L.; Toporowski, P. M.; Fetters, L. J .; Huang, J . S.; Lin, M. Y.; Hadjichristidis, N. Macromolecules 1994, 27, 3821.

(34) Vlassopoulos, D.; Fytas, G.; Pispas, S.; Hadjichristidis, N. Physica B 2001, 296, 184.

(35) Roovers, J. Macromol ecules 1994, 27, 5359.

(36) Segrè, P. N.; Meeker, S. P.; Pusey, P. N.; Poon, W. C. K. Phys. Rev. Lett. 1995, 75, 9580.

(37) Phan, S.-E.; Russel, W. B.; Cheng, Z.; Zhu, J .; Chaikin, P. M.; Dunsmuir, J. H.; Ottewill, R. H. Phys. Rev. E 1996, 54, 6633.

(38) Bodnar, I.; Silva, A. S.; Deitcher, R. W.; Weisman, N. E.; Kim Y. H.; Wagner, N. J . J . Polym. Sci., Part B: Polym. Phys. 2000, 38, 857.

(39) Metzner, A. B. J . Rheol. 1985, 29, 739. 
(40) Happel, J .; Brenner, H. Low Reynolds number hydrodynamics; Martinus Nijhoff Publishers: Dordrecht, The Netherlands, 1983.

(41) Russel, W. B.; Saville, D. A.; Schowalter, W. R. Colloidal dispersions; Cambridge: New York, 1989.

(42) Krieger, I. M. Adv. Colloid Interface Sci. 1972, 3, 111.

(43) Quemada, D. Rheol. Acta 1977, 16, 82. Quemada, D. Prog. Colloid Polym. Sci. 1989, 79, 112.

(44) Rietveld, I. B.; Bedeaux, D. J . Colloid Interface Sci. 2001, 235, 89.
(45) Graessley, W. W. Adv. Polym. Sci. 1974, 16, 1. Utracki, L.; Simha, R. J. Polym. Sci. Part A 1963, 1, 1089.

(46) Buitenhuis, J .; Foerster, S. J . Chem. Phys. 1997, 107, 262

(47) Mewis, J .; Vermant, J . Prog. Org. Coat. 2000, 40, 111.

(48) Buscall, R. Private communication, 2003.

(49) Borrega, R.; Cloitre, M.; Betremieux, I.; Ernst, B.; Leibler, L. Europhys. Lett. 1999, 47, 729.

(50) Frith, W. J .; Lips, A. Adv. Colloid Interface Sci. 1995, 61, 161.

MA0355150 